\title{
Augmenting The Bench
}

\author{
Carola Moujan
}

\section{Introduction}

- - - - - - - - - - - - - - - - - - - - - - - - - - - - - - - - -

The possibility of coupling material objects and data opens up new perspectives in street furniture design. Many cities throughout the world are undertaking full-scale experiments so as to define and grasp the role and function of a new kind of public equipment. This equipment is expected to improve living environments with new qualities and functions made possible by technological advances. Augmented reality, situated media, orientation services, and other information-oriented displays are among the most common forms taken up by city-makers - their deployment within the city however, is not without issues. This paper argues that the technology-driven, content-oriented, screen-based paradigms that underpin most devices today overshadow more powerful and productive design approaches. Displacing the focus from content to relationships, and through the case of Luciole - a network of augmented public benches - I will consider under which conditions digitally augmented furniture can support place-making practices, expanding them in forms that are both novel and authentic.

The first issue stems from the assumption that by adding digital information into a physical location, the place itself is automatically improved and affirmed. This correlation does not take into account a most basic requirement in any sustainable urban policy: place-making. In their seminal work Body, Memory and Architecture, architects Kent Bloomer and Charles Moore describe "placeness" as a distinctive quality present in some spaces that is not defined by physical dimensions, services or functional attributes alone, but rather by its capacity to remain itself in spite of the variation of its parts (Bloomer \& Moore 1977: 107). More recently, Jeff Malpas has further developed the dynamic and productive value of such placeinherency, stressing "the content or character that belongs to place is also such that it encompasses that which is present within it" (Malpas 2015:4). This proposition suggests that an inquiry is needed into the relationship between information and placeness. Moreover, it causes me to ask: in what ways can information contribute to, enhance, or even generate, feelings of "being there" as a characteristic of true place experience?
A second issue concerns the role of screens as material objects. Since information-oriented services require displays of various sorts, and because there is growing demand for information-rich environments, screenpresence is on the increase within urban landscapes. Two questions arise here: firstly, are generic screens adequate for urban place-qualities? and secondly, given that screens have typically been developed in the context of interior spaces - rather than being shaped by urban practices and functions like mailboxes, benches, light poles, and other traditional street furniture - what form should the distribution of digital information take? At stake in urban situations is loss of coherency built up over time, but also that such devices assume the form of advertising screens thereby adding to the apparent commercialisation of urban place. The recently renovated SaintLazare station in Paris illustrates exactly this problem. Opened in 1837, the station had remained mostly unchanged since the 1970s, when the first commercial area was created below the Salle des pas perdus, the station's main hall. In 2003, the railway company undertook a vast transformation meant to last until 2012 that included a full reprogramming of the Salle des pas perdus, which itself became a shopping area. The new commercially orientated [station] design incorporates a dense number of advertising screens that tend to overwhelm the legibility of the original built form. The markers of 'station' as an identifiable place become difficult to ascertain. In his popular blog, French artist, developer, and teacher Jean-Noël Montagné reports being accosted by a woman, visibly distressed, presumably late to catch her train, desperately asking where the station was, "because here, we are in a kind of shopping centre, right?"1 Whilst such confusion is unlikely to persist as populations become accustomed to this new commercial station typology, the situation highlights the erosion of a station's transitional space and begs the question: how many screens can a space hold without sacrificing its identity entirely?

Beyond private appropriation of the public realm is the accumulative cluttering, and redundancy of objects. Implementing new screen-based services often means removing older equipment, yet what is to be removed in order to make the necessary space is crucial. While dislodging static maps or obsolete phone booths does not meet much resistance, the progressive disappearance of public benches raises much concern. ${ }^{2}$ In the $21^{\text {st-century }}$ 
city, the smartphone has taken the place of public phones and printed maps. But this functional advantage can come at the price of isolation; after all, asking strangers for directions, or queuing to make a call was often the starting point of interpersonal exchange. However, I am not suggesting that we should go back to the previous state of things; rather, I am gesturing towards a framing of digital augmentation that does not automatically imply addition (of services, content, surveillance...) but considers removal, in the sense of 'making room' for something meaningful to happen.

Because of the close alignment between digital billboards and outdoor advertising, there is a tendency to associate all screen-based services in such situations with advertising surface. It was the case during the experimentation of nAutreville, a full-scale augmented reality panel presented within the MUI program conducted by the city of Paris in 2012, to which I contributed as a member of the design team. ${ }^{3}$ As we discussed the project with local users, I was struck by the distrust expressed by many neighbourhood residents despite the device containing no advertising at all. In my design work, I had been focusing mainly on content structure, information architecture and interaction principles, but users' reactions made me realise that there might be an issue with the screen itself, no matter how engaging the content and refined the interface. The problem here seems to be a global advertising overload that citizens are beginning to reject, and the fact that digital urban screens seem to almost inevitably include commercial messages. Reducing the issue to the sole critique of merchandising, however, would make us fall back into the content-based framing from which I am trying to depart. ${ }^{4}$

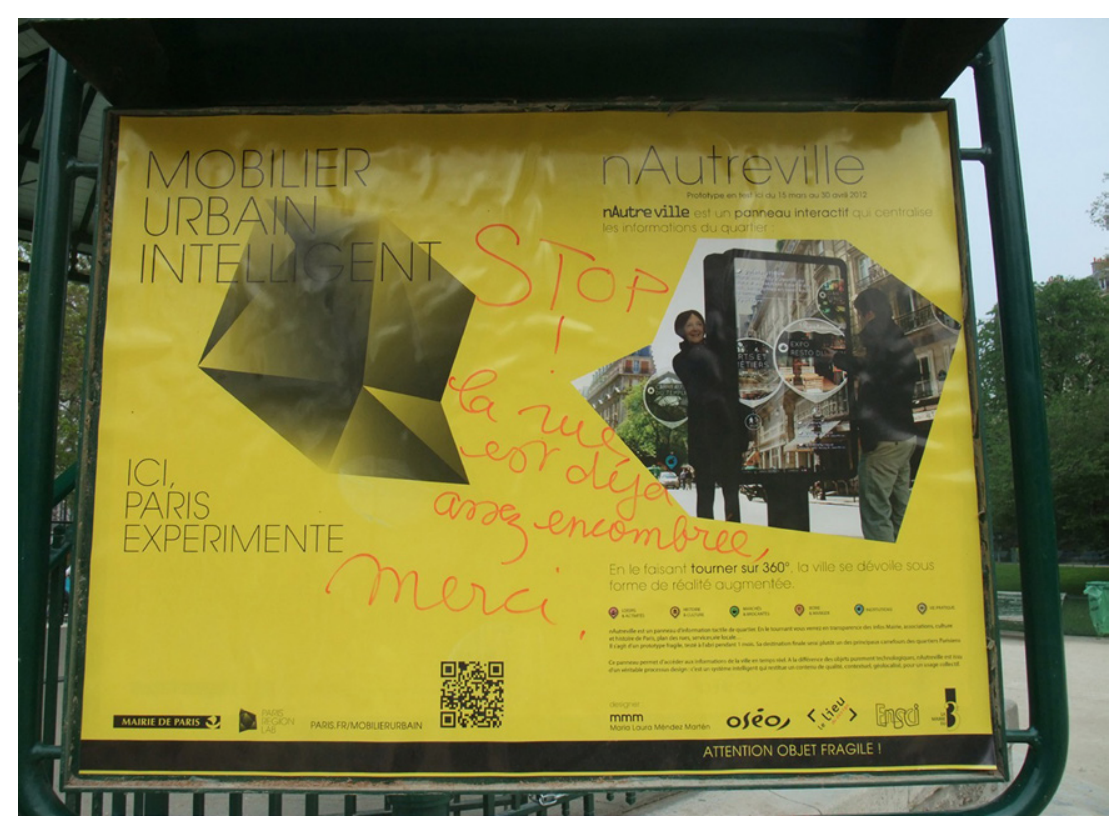

Fig. 1

Scribbling on advertising poster for the MUI program, reading 'Stop! The street is crowded enough already'. [Photo: Maria Laura Méndez-Martén, 2012, Paris]

If we envision the notion of 'digital augmentation' as content, we cannot break away from the screen-based paradigm. But I am not suggesting that any use of screens in urban space leads to an impoverishing experience. Projects such as Urban Echo by LustiLab (2006), where an array of cameras and screens located in different neighbourhoods across the city enable accidental encounters of a new form (as passers-by happen to cross each other in a sort of digital limbo), offers a good example of meaningful use. The aesthetic power of the project does not derive from telematics as a technical possibility, but instead, and significantly, from the uncanny feeling of continuity induced by the 'screen-within-the-screen' effect, which effectively triggers a feeling of spatial extension. ${ }^{5}$
From a theoretical standpoint, many authors ${ }^{6}$ have pointed out the new spatial possibilities opened up by screen technologies, yet this paper questions the formalities of the screen-centred design and asks: is it possible to think of digital design without screens? What does it imply for design practice? How would this modify the way we envision augmentation and, more generally, the experience of urban space? Returning to the point that digital urban furniture is driven by an assumption that places can be improved with access to more "information", the screen-based paradigm reveals something of a blind spot in the way we envision digital urban interaction today. Here I ask how information threads, maps, notifications from social media, etc. affirm the feeling of place-connection or "being there". Following Heidegger's Dasein, French philosopher Henri Maldiney notes that the time and place of the aesthetic experience is always 'here and now'. An aesthetic experience is an event, which, as such, does not happen in time, but founds time. For Maldiney, when the question of being in the world meets that of being the world, the issue is not to gather information about it, but to exist with it and within it, "to be co-born" [co-naître] ${ }^{7}$ with it. Can we consider then that, the digital information is present, but in a different sense, "the primitive, most concrete sense of the word, where 'to inform' does not mean to 'transmit knowledge' but instead, to 'give form'” (Maldiney, 1986: 27). Information as content, and information as structure can be distinguished as formerly a focus on components, and latterly as potential to trigger and orient processes. Embracing this distinction informs design as a discipline beyond material shaping and specific problem solving towards designing places by way of structuring underlying forces of a given situation in order to enable an emergence of augmented urban forms and relations. How then do these digital information technologies contribute to 'give form' to place? Further, to adapt Joseph Rykwert's proposition, what if the goal of urban design is to "find some place in all this space" (Rykwert 2002: 3)? As such, the value of digital augmentation in the urban realm (for example digitally augmented urban furniture), ought to be considered placeformation rather than information. Such a distinction asserts the difference between a technical object and an aesthetic experience, thus making explicit the specificity and importance of design beyond function or service.

\section{Dis-placing the Digital: From Interface to Interspace}

In his influential essay Hertzian Tales, British designer and theorist Anthony Dunne defends, through the concept of post-optimal object, a vision where the design of digital and electronic objects "facilitate[s] more poetic modes of inhabitation" (Dunne 2006: 20). First published in 1999, Dunne's essay directly opposes the dominant ethics of "user-friendliness" and suggests, following Adorno, that "user-unfriendliness" (which is not to be confused with user-hostility), is essential in any aesthetic experience (Dunne 2006: 35-36). Whilst Dunne's work has catalysed interesting design work, what he terms post-optimal objects are still focused on entities, not experiences. Heidegger's distinction between objects and things helps in the consideration of digital augmentation of public space. A thing implies all the links that exists between beings, while an object is an abstraction, something considered independently from any environment. To think past the technologically grounded 'optimal object' (i.e., an object understood as functionality and practicality optimal), but still deploy Dunne's emphasis on aesthetics, we need to understand where the precise distinction between an aesthetic object and a technical one lies. Gilbert Simondon has discussed this difference in terms of relationships, more precisely, in terms of qualities of inscription within the world, showing that the kind of abstract framing that considers 'objects' instead of 'things' is typical of technical activity. The fact that a given system performs steadily regardless of context is precisely what characterises a good technical object (Simondon 1958: 
183). However technical performance alone offers little to the life in public places. Design, as not solely a problem-solving activity, but an aesthetic one, must articulate the relationships between any technological system and its environment so that "it is no longer the object that is perceived, but the world, [itself] polarised in such a way that the situation makes sense" (Simondon 1989: 89).

Similarly, Tim Ingold has described places as "complex knots" where multiple lines of life meet: "lines are bound together in the knot, but they are not bound by it" (Ingold 2007: 100). In contrast with the abstract, predetermined framing described by Simondon for technical activity, Ingold's emphasis on preposition suggests a mode of relationship that springs from intrinsic, dynamic, spontaneous encounters. To consider places as things, then, implies taking into account the multiple lines that meet there from the perspective of their inter-relationships - to envision them not as always available, ready-made experiences, but instead, as events that emerge at a particular location at a given time.

Consequently, and despite current terminology, adding information, digital services, equipment, wifi access or free terminals to a physical setting does not automatically augment nor consequently improve urban place. There appears to be confusion between "augmentation" and "addition"; two concepts that fundamentally differ in nature. The term "augmentation" expresses a qualitative improvement that is not dependent on addition, which is a quantitative notion. Leaning on Simondon's distinction between technical and aesthetic activities, we can envision augmentation as a form of polarisation of space through design, and where an initially chaotic, undifferentiated condition shifts towards a spatial event that I have called interspace [entr'espace]. An interface is a technical word referring to an object that provides access to, and navigation through, heterogeneous layers of information. Within this framing, each technological component preserves its own distinctive identity. An interspace [entr'espace], on the other hand, implies the experience of multiple dimensions co-existing within an integrated perception of reality (Moujan 2011, 2014). It is unity that makes the difference between addition and augmentation. While the concept of interface is defined and described in relation to its components (content, hardware, software, user...), the notion of interspace [entr'espace] refers to a unique quality that does not come from the parts themselves but, instead, emerges from the complex relationships between the parts. "Such relationships produce a new quality, which is 'design'” (Moholy-Nagy 1947: 42). Thus achieving unity - or what amounts to a meaningful whole despite variation of parts - is precisely the design task. Designers create experiences; and the defining characteristic of an experience is a pervasive, distinctive quality that gives it its name (Dewey, 1934:38). Hence, the concept of interspace [entr'espace] is a conceptual tool that steps from the technically grounded terminology that dominates the digital design field. Precisely because of its technical roots, the vocabulary of interface inevitably focuses on components and the physical/digital dualism, using common expressions such as "hybrid space", "virtual reality", "interactive art". But language can be an obstacle to the emergence of novel and authentic forms of augmentation. Making this distinction is not only a matter of conceptual rigor but one of practise; words are tools, design tools. From an interspace [entr'espace] perspective, augmenting space is therefore not a question of adding something to a pre-existing base, but rather of setting up a field of tensions sufficient for triggering a spatial event. Much like what happens in an electromagnetic field, within interspaces [entr'espaces] components lose their substantial identity, disappear as distinct entities in order to make room for an experience.

\section{The Forces of Origin}

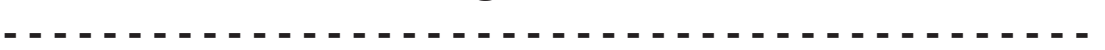

How can such event-triggering be achieved? Following Leibniz and Whitehead, Gilles Deleuze (1992 [1988]) notes that an event emerges from chaos provided that some kind of sieve intervenes. The sieve Deleuze refers to can be defined as an agent through which the site's underlying forces are polarised and directed, allowing the emergence of a singularity, the specific kind of spatial form we name "a place". Deleuze notes that neither chaos nor the sieve pre-exist each other; rather, chaos is a pure Many, a disjunctive multiplicity, that the sieve, described using the image of an electromagnetic field, makes become a singularity. Let us call that sieve, following Walter Benjamin (Benjamin 2003 [1928]), origin. Inspired by Husserl, Benjamin's concept of origin does not relate to a chronological beginning but instead refers to a generative force, a source or cause. The notion of origin can itself be examined through the place-as-force-field metaphor. The initial question Husserl considered in The Origin of Geometry (1954), is analogous to the one I raised earlier in relation to placeness: what is it that gives geometry its unity in spite of the variation of the component parts? Why do we speak of a singular geometry instead of plural geometries? The concept of origin comes precisely in order to define the source of an active identity, perceptible as a pervasive quality present in the individual parts as well as in the whole - something I referred earlier as being typical of real places. Benjamin (1925) develops the notion further demonstrating that it is in regards to origin that authenticity can be established.

Let us follow the vectors now. In Husserl's originary geometry, edges are blurred. Proto-geometric shapes are anexact, that is, inexact by essence, not by chance. It is because of, and thanks to, their lack of exactness, that there can be many geometric shapes within one geometry. Deleuze and Guattari critique Husserl's analysis of anexactness as a primitive, less evolved state of geometry, considering that there is more, not less, in anexact forms than in exact figures. This distinction recalls the one Richard Sennett makes between a border and a boundary. As he notes there are two different kinds of edge: "In Natural ecologies, borders are the zones in a habitat where organisms become more inter-active due to the meeting of different species or physical conditions". Conversely, "the boundary establishes closure through inactivity, by things petering out, not happening; to say that the edge-as-border is a more open condition means it is more full of events in time." (Sennett 2010:267). Following this stream of thought, augmenting through design evokes thickening and extension. Extension, notes Deleuze, is the first condition of the event; "[it] exists when one element is stretched over the following ones, such that it is a whole and the following elements are its parts. Such connection of whole-parts forms an infinite series that contains neither a final term nor a limit (the limits of our senses being excepted)." (Deleuze 2006: 87). It is in this sense that a place's quality or character "encompasses that which is present within it", as Malpas puts it - or to use Maldiney's phrase - it "founds time". ${ }^{8}$ This not only means that potential directions of spatial augmentation derive their source from what is already there rather than external content, but also, that the difference between addition and augmentation is a question of dynamics. Addition amounts to accumulation and is static in nature; on the other hand, augmentation constitutes a form of production - it amasses organically. Through this lens, the concept of place itself appears as a form of augmented space. The idea of a digitally augmented place, then, suggests the possibility of further development of a place's core qualities in novel directions that were unconceivable before. Hence, the notion of origin provides a grounding for a theory of digital augmentation based on 
the authenticity of the relationship between the physical location and the extensions triggered by the digital.

We need now to understand how this is done. Quite significantly, and in spite of their numerous disagreements, ${ }^{9}$ both Benjamin (1990) and Heidegger (1993) envision origin through the image of a void, or "making room". In both cases, productive tension is central. For Benjamin though, destruction is the decisive act of production and is more important than the actual things to come. For Heidegger, instead, the void makes room for something, something that dwells, in the context of a symbolically organising fourfold. Whatever interpretation we might choose, it is clear that some form of under-determined openness is required for augmentation, further stressing the idea that content or technology as such have little to do with it. Rather, it is in the sense of "bringing-forth", of revealing, of opening up, that digital technologies are capable of entering into the event of augmentation. It is also in this sense that design aligns with techné. As Heidegger notes, "what is decisive in techné does not lie at all in making and manipulating nor in the using of means, but rather in the aforementioned revealing. It is as revealing, and not as manufacturing, that techné is a bringing-forth" (Heidegger 1993: 13). Interspace [entr'espace] as augmented space, then, comes to existence through revelation rather than construction; what is opened up by it, within it, and through it are a space's underlying forces, potentialities and tensions. Itself an event, it brings forth such qualities, which, structured and polarised, extend over space, colouring it in ways that are both archaic (because they are rooted in origin) and novel (because they did not exist prior to the event of bringing forth).

\section{In-between PIacemaking}

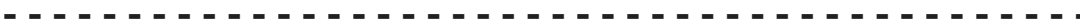

With their multiple functionalities, news feeds, and alerts, digital objects often drive us away from the unique atmospheres, mystery, and unexpected encounters that make the wealth and delight of urban experiences. Given the above considerations, it warrants asking if it is possible to envision augmented objects that instead reinforce and enhance the capacity of 'being there', and, through continuous engagement with the place, expand the objects' core qualities? In previous articles (Moujan 2014, 2015), I have compared examples of digital augmentation projects based on, and respectful of, origin, with others driven by function, content or technology. The examples were chosen from existing places with wellstructured identities; in all those examples, the design challenge was to recognise, respect, connect to, and possibly expand, an existing origin. But what about spaces that are not yet places? Is it possible to build origin through digital design? My contention is that, because of the capacity of digital objects to structure urban dynamics, to orient forces, they can act as triggers for new origins. The periphery of many major European cities today offers a particularly fertile field to further examine this issue. Very large urban areas will endure long periods of construction work during which inhabitants will have to adapt to uncomfortable living conditions and loss of known reference points. What will happen with those contexts during transition? Is it possible to envision them as real places, albeit their impermanent nature? To respond to this challenge, most cities rely on communication about the expected results and effects. Such strategies often involve fragments of in-site storytelling, and digital technologies play an important role in this type of initiative (an example being the realistic computer renders printed on worksite's fences that show what the place will look like once the works are finished). Sometimes, more sophisticated representational systems are used. Augmented reality seems particularly suited for this purpose, for it pulls visitors away from the messiness of the here and now, and projects them into the bright future planners have envisioned. Instead of discussing here the mechanism and value of this type of initiative (something that demands case-by-case analysis), I would like to adapt my own initial question to this particular example and ask whether is it possible at all to use digital technologies to enhance the experience of 'being there', while simultaneously transforming and re-defining what "there" means - contrary to projecting users into a different place, in a distant future? Beyond narrative, what other forms of digital place making can be explored?

Luciole (French for "firefly") is a network of reactive, luminous, connected public benches that suggests such a possible alternative. The project was first intended to reinforce the sense of place in misused, neglected or intransition areas through a network of elements that gather relations and build new ones. Comprised of a metal structure, a cocoon-like seat made of metallic mesh and optic fibre, sensors, an Arduino board, and a light generator, each Luciole bench diffuses light and tweets in response to its own occupancy as well as that of other benches in the network. Just like fireflies, Luciole benches catch the eye, inviting users to engage in a path or to make a stop, triggering new circulation dynamics and poetic atmospheres.

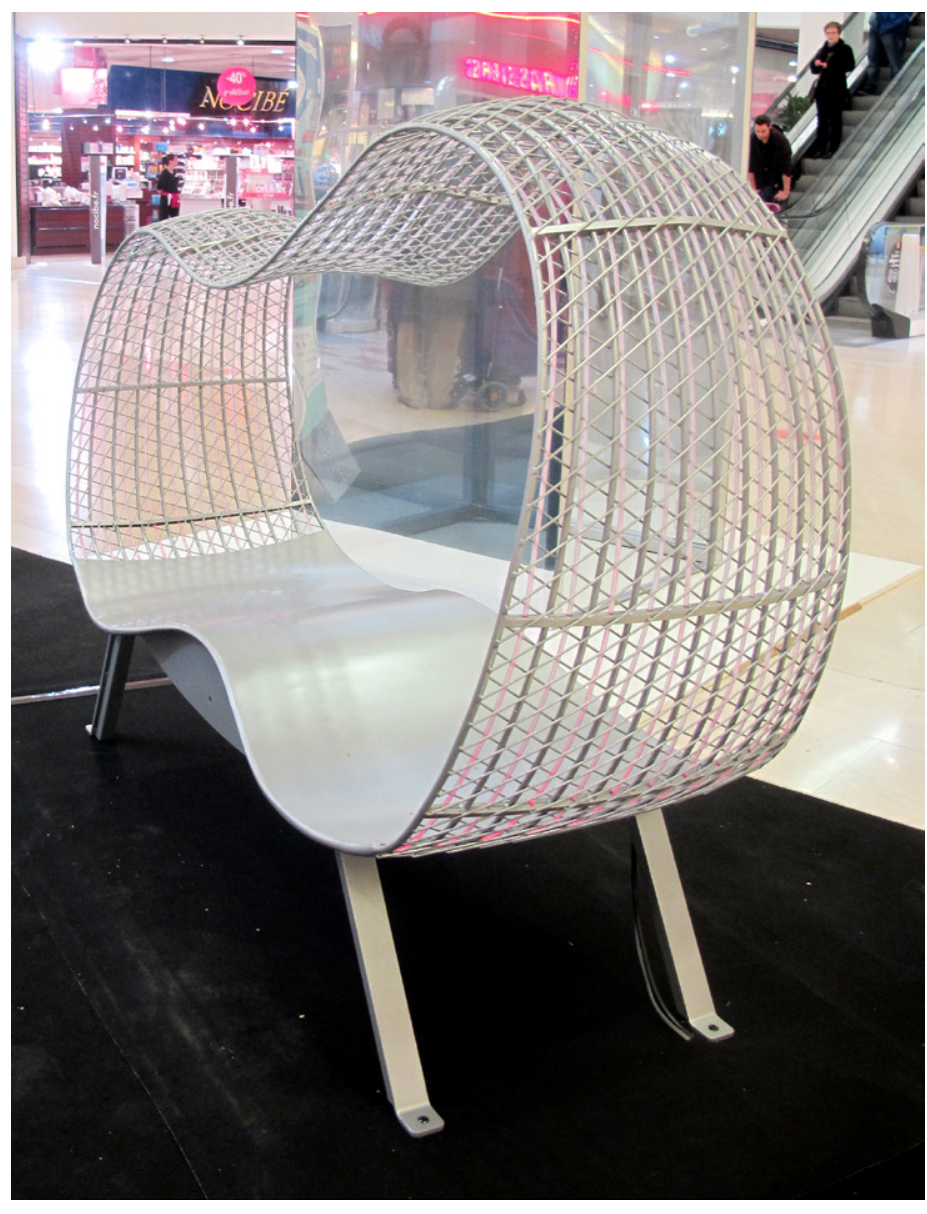

Fig. 2

Luciole. Connected public bench prototype. [Photo: Author, 2015]

In contrast with the imposing form of solid digital screens, Luciole has been designed to merge with existing urban contexts. This possibility comes from hollowness (of the benches' bodies and of the steel mesh that composes 
them), combined with the specifics of the materials. Stainless steel reflects and diffuses the light carried by the optic fibre, while the intertwined mesh and fibre complex creates a blurred effect as light variations affect the perceived opacity of the metal. In terms of form, its cocoon-like shape induces feelings of intimacy, making Luciole a transitional space, inbetween the public and the private. At a local level, each Luciole bench responds to sitting and to movement in the immediate surrounding by changing light colour and intensity. On a network level, the benches communicate with each other, sending local messages every time someone sits or leaves, and responding through light modulations. This particular feature, of little practical value, affords firstly, peripheral awareness of other people's presence to convey a diffuse feeling of togetherness and secondarily, a wrapping of users in a luminous halo, particularly valuable at night when illumination is key in transforming a place's atmosphere. Yet during the day, it plays a less apparent role in structuring the experience. Light variations keep users aware and connected to surrounding activities without attracting their direct attention, thus, enabling them to remain free to chat, read, or just relax instead of closing them within the halo of a screen. Simply put, participants can benefit from connectedness without giving up immediate presence.
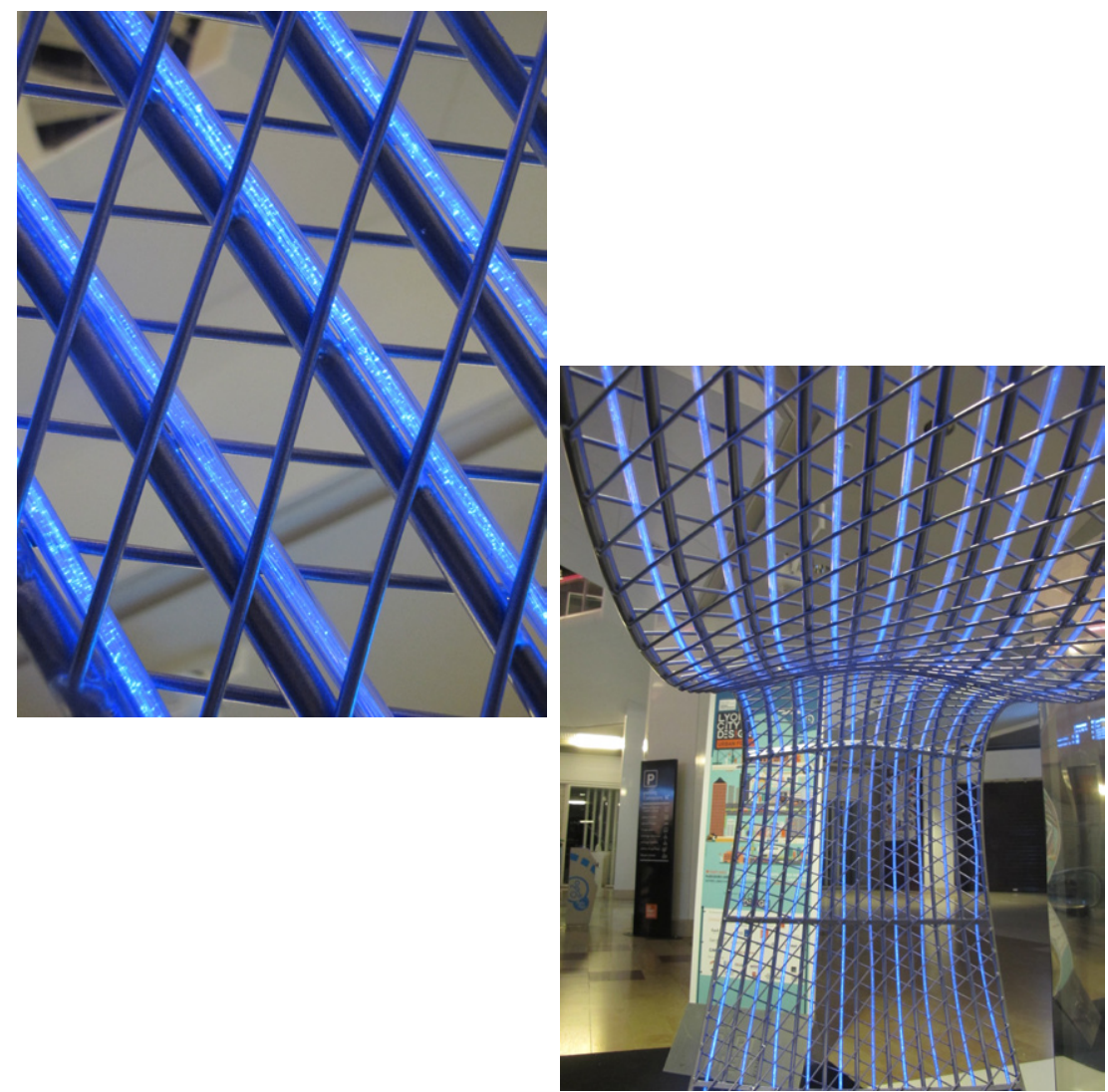

Figs 3 \& 4

Light and material details. [Photos: Author, 2015]

Y et the value of this design may have further to offer on a deeper level; in his canonical essay Designing Calm Technology (1996), Mark Weiser wrote that "the most potentially interesting, challenging, and profound change implied by the ubiquitous computing era is a focus on calm". For Weiser, the key to calm technology lies in the articulation between the centre and the periphery of attention. Broadly misinterpreted at the beginning,
Weiser's theories have regained interest in recent years. His core idea is that if instead of just considering the foreground, we use design to trigger dynamic back-and-forth movement between the centre and periphery of attention, users will be enabled to stay in control and respond by switching focus when necessary. Unlike screen-based devices that continuously rely on direct attention, Luciole's light behaviours are designed to remain diffuse and peripheral until a change in focus is required, thus making it a potentially calming piece of technology.

Because of its collaborative lighting system that responds to occupancy at distance, Luciole invites playful and unexpected social interactions. However, many urban encounters come with tension, and frequently anonymity is desired. Often enough, we may even simultaneously desire and reject the idea of being with others, an ambiguity that traditional bench design cannot respond to. But, because of the interaction it affords at various distances, Luciole reveals an interstitial dimension of placeness, one where users can connect and take part in a collective activity while still preserving interpersonal distance. Augmentation here brings forth the possibility of taking a seat with someone without actually sharing physical space.

On a larger scale, Luciole benches are connected to the internet; after retrieving real-time urban data, they flash lights and tweet context-relevant information such as time remaining until the next tramway reaches the nearest stop, or the number of bikes available for rental, in order to make the most of urban journeys. At the moment Luciole's users are ready to leave, the information they need to make the next move comes into focus. Instead of having to look at a smartphone's screen, information is in the periphery and only reaches the centre of attention when relevant.

Finally, Luciole's tweets, another seemingly useless feature, offers an additional level of interlinking to the experience of sitting in a public place. Tweets constitute a real-time record of a micro-urban atmosphere, the kind of "small" data that adds to the texture of life. Luciole's twitter feed makes visible the rhythm of a place and provides, once again, peripheral information that can become important at some specific moments. A local neighbour, for instance, might want to know whether there are available seats before going down to the park; a researcher studying social dynamics might use the tweets to build data visualisations to figure out activity patterns; passers-by might want to signal their presence so that local Twitter friends can join them... Moreover, Luciole's messages constitute structured data that could potentially be integrated within a larger network. This means envisioning street furniture in terms of ecosystems rather than individual uses or services; or, to put it in another way, to design things, not objects.

Selected through an open call, a first prototype of Luciole was built and shown during Lyon City Design Urban Forum, which took place between March 19th and April 2nd, 2015 in Lyon (France) as a part of the Saint Etienne International Design Biennial "off” program. While a longer and rigorously structured study would be necessary to confirm the entire hypothesis, preliminary observations show that users respond very positively to the system. During the event, multiple forms of unexpected appropriation happened, not only in terms of use, but also of body attitudes, which seemed more relaxed and spontaneous than those observed in regular benches. Beyond technological obsession, Luciole proposes an interpretation of Dunne's post-optimal concept discussed earlier. With a departure from the function and efficiency ideal that rules much digital product design today, Luciole explores the poetic possibilities of open data and the Internet of things that might be revealed when used to weave dynamic and delicate relationships between the object and its environment. 

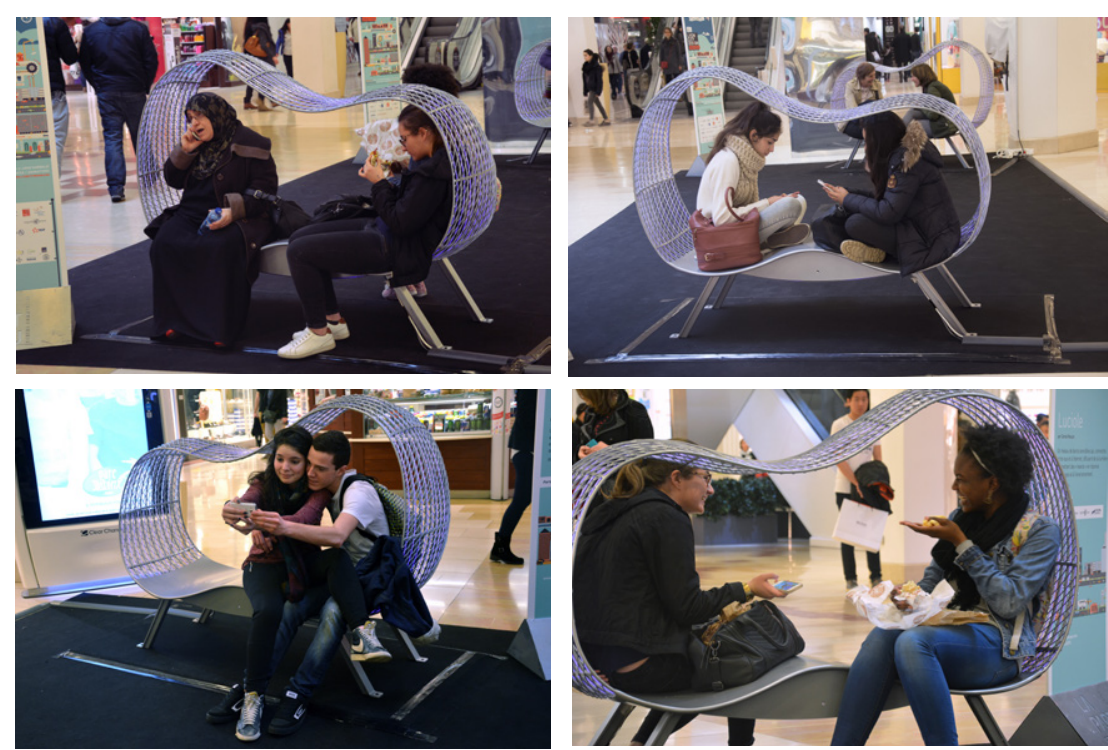

Figs 5, 6, 7 \& 8

Examples of user appropriation during Lyon City Design Urban Forum. [Photos: by Author, 2015]

\section{Telematic atmospheres}

Luciole's telematic principle can be seen as analogous to previous artistic experiences with connected benches. Artist Paul Sermon has been working with telematics since the 1990s, connecting distant people in various ways, often enabled through a specific use of materials that gives his work strong tactile qualities in spite of its visual base. In Telematic Dreaming (1992), Sermon uses a customised video-conference system to project the image of each member of a couple of distant lovers onto the other's bed; the irregular and soft surface of the bed dissolves hard edges and overly realistic effects in order to produce a blurred, dreamy atmosphere. In some of his more recent pieces, telematics take the form of "urban encounters", like in Urban Picnic (2010), where people in two distant public areas are brought together for a shared meal. The participants' behaviours differ from what one can be used to seeing in a regular picnic. According to Sermon, "the work encouraged visitors to be playful, interacting with others and the environment in a way that they would not otherwise have done". ${ }^{10}$

Although both Luciole and Urban Picnic rely on the ambiguous quality of telepresence as a form of distant proximity to trigger social exchanges that otherwise might not have happened, the meaning of distance differs. In Sermon's projects, participants are separated by considerable distance the point is, precisely, to be at once somewhere and elsewhere. Luciole, in contrast, connects people who, although physically separated, are within visual reach. The goal is not to take participants away from the here and now but, instead, to enhance the feeling of 'being there' through a revealed interspace [entr'espace]. Light is not used to represent distant presence; the intention instead is to produce a shared visual atmosphere. A sense of togetherness is induced through a sensorial - rather than symbolic - effect.

Perhaps closer to Luciole in spirit is 21 balançoires, a 2011 project by Montreal studio Daily Tous les Jours. First meant as a temporary installation during construction works in the Quartier des Arts in Montreal, the piece features a group of 21 connected swings that, through music and light, function as a collective instrument. The designers worked with Luc-Alain Giraldeau, an animal behaviour professor from the Université du Québec, to explore the concept of cooperation. Participants can use the swings individually; they will light up, emit sound and - last but not least - provide the kind of amusement any swing does. When used in collaboration, however, the system works as a real-time musical instrument capable of playing elaborate tunes and light patterns. As a result, a remarkably inclusive installation that "stimulates ownership of the space, bringing together people of all ages and backgrounds, and creating a place for playing and hanging out in the middle of the city centre". 11

In comparison, Luciole's discrete playful dimension is somehow more diffuse, underdetermined, as are its social ambitions. It does not affirm collaboration as an ultimate goal, since such approach leaves out the possibility of interaction between people not willing to collaborate, such as the marginal, the anti-social, or the aggressive. Ultimately, its intentions are to "make room" for unexpected, unpredictable interactions that could even accommodate hostility, but in a way that brings forth the productive power of tension. Instead of framing a pre-determined form of desirable social encounters, an anexact manner of playing is involved here, that is, a way of playing that is neither based on rules, nor on a potential reward..$^{12}$ The goal is less to bring people together in active collaboration and more to reveal an invisible shared space between them. Participants may, or may not, choose to get involved in a common activity within this interspace [entr'espace], and the forms such activities might take are unpredictable. Moreover, the benches do not play, like Urban Picnics tables do, as symbolic elements meant to convey a specific meaning; neither is their function to build a whole new situation, as is the case in 21 balancoires where the original swinging for swinging's sake becomes a way of playing music. Luciole's main function remains that of a public bench, only augmented, but in a sense meant to enhance the object's original potential and meaning. The goal is not to make an exceptional intervention in public space, but instead to become a permanent piece of street furniture - something that requires a more discrete, lighter approach.

$\mathrm{O}_{\mathrm{n}}$ another level, the major difference between Luciole and other projects based on local networks is that it connects multiple networks together, across different scales. Whilst the light connections on a local level are assuredly the feature that has the strongest direct impact, the tweets and data retrieval from local services makes Luciole a meeting point for multiple spatial and temporal dimensions. This might seem anecdotic from today's perspective, yet transforming usual urban objects into sensors might be a clue in the multi-faceted path to building more resilient cities. Instead of being just another isolated, albeit playful, network, Luciole becomes a constructive element in a broader urban eco-system.

\section{Augmenting the Bench}

Greatly overlooked, the question of authenticity is of major importance for digital design. Following Walter Benjamin, authenticity in the age of digital reproduction cannot be established otherwise than in terms of internal relation to origin. Benches are icons of a certain understanding of what living together in the city might be; they are themselves powerful placemaking tools. Benches have history, for they are places where people have met, kissed, slept, read, and daydreamed. Therefore, to augment a public bench is not a question of adding elements such as power plugs, images, services or functions but, instead, of respecting, revealing and expanding its core qualities. Is this possibility restricted to the solely digital realm? Of course not. There is a bench in the Rosedal (a rosary in the 
Palermo neighbourhood of Buenos Aires) that does not rely on the digital for augmentation. Like other benches in the park, its overhead pergola is wrapped by rose plants that, in the right season, augment the experience with a delicate perfume. But this one is special: when sitting on it, users can hear stories by Borges. Palermo was Borges' home and inspired much of the uncanny ambiance of his writing; in return, his universe has become inseparable from the neighbourhood's identity. So sitting on that particular bench augments the experience of the Rosedal, opening it up and extending it to the whole neighbourhood and beyond.

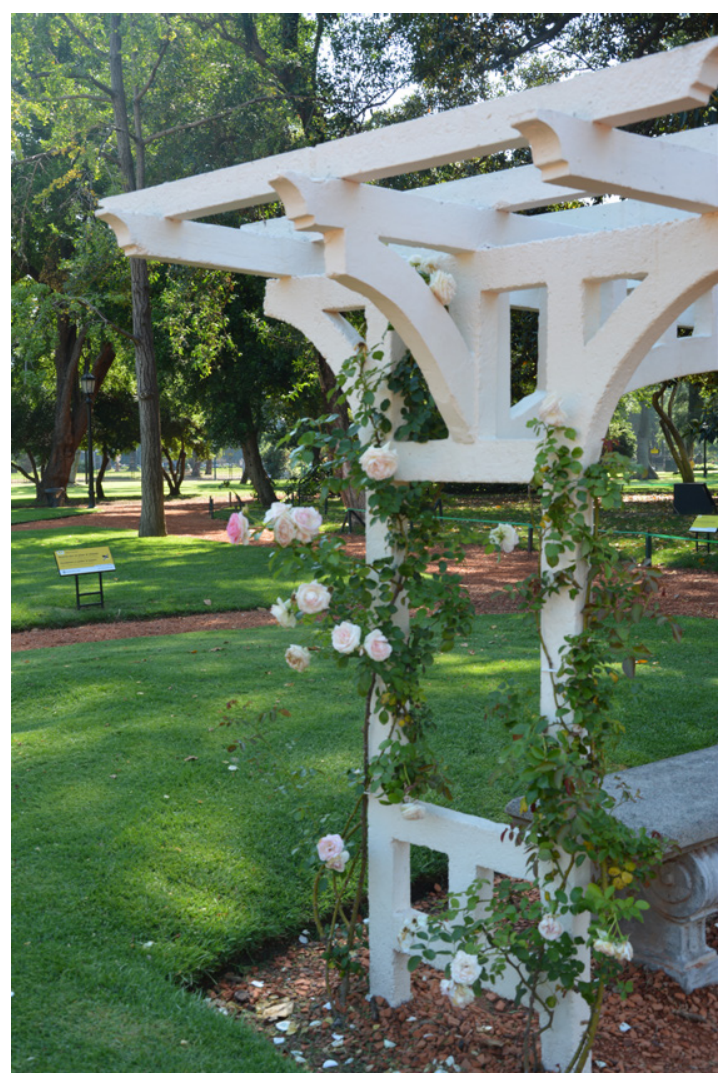

Fig 9

The augmented bench in Buenos Aires' Rosedal. [Photo: Author, 2015]

Digital technologies introduce new possibilities of modulation, of development and co-construction over time which, when deployed in dynamic ways, have potential to expand the limits of form. I have asserted the current material/digital divide is a barrier to new directions. Looking to the near future, it is likely the physical/digital dualism will be obsolete and new understandings of the role of computing will arise. As such, screenbased devices will no longer be the only gateway; city dwellers may be freed from their current tethering to smartphones and mobile devices without having to give up connectedness and smartness. ${ }^{13}$ The main concern will no longer be exclusively about information content or technological performance, but, instead, how to achieve higher levels of consciousness in other words, how to be fully aware, here and now. ${ }^{14}$ It is conceivable that cities of the future will be defined far less by physical boundaries; they will shrink, move, transform, mutate, leaving gaps and voids. Impermanence will be the norm and atmospheres mutable. To respond to this new challenge, urban design ought to adopt new strategies that rely less on planning, physical intervention, and control, and more on the force of origin, ${ }^{15}$ respecting and preserving it when it is already there, and setting up the conditions for its emergence when it is not.

To survive, future cities will have to be resilient, but urban resilience and sustainability are a matter of energy flow and interlinking, ${ }^{16}$ not of materials or technologies or processes as such. The city of the future will see awareness of this fact grow. Networks will be ubiquitous; they will no longer rely only upon public infrastructure, nor on centralised platforms. Instead, complex, guerrilla-like, unstable meshes will pop-up. People, living beings, "objects", will be more interdependent than ever, and relational ecologies will become central. For this city, the augmented public bench may be understood as a test probe, one that extends the horizon of the conceivable without breaking the link with a place's identity. 


\section{Endnotes}

- - - - - - - - - - - - - - - - - - - - - - - - - - - - - - - - - - - - - - - - -

1

http://hyperbate.fr/dernier/?p=19706. Accessed October 5th, 2015.

2 In the 18th arrondissement, a popular district in Paris, for instance, residents organised in January 5 th, 2013, a cardboard bench sit-in to protes against what is perceived as a hidden attempt to eliminate spontaneous gatherings in public places. https://quartiersentransition.wordpress.com/2013/01/05/lejour-ou-les-bancs-publics-ont-repris-paris/. Retrieved June 2015.

$3 \quad$ More information about this project (in French) at www.nautreville.com

4 Julian Oliver's Artvertizer (2008) is an interesting counter-example. Described by the author as "improved reality", the project - an advertising hacking system of sorts- superimposes images onto advertising surfaces. Participants look through goggles with markers which, when correctly aligned, create a visual illusion that replaces the advertisement with a work of art. In terms of content and message the effect is powerful; but the project does not address the issues of spatial impoverishment and isolation.

"Webcams allow you to see into another space, mirrors allow you to see your own space. Using billboard screens and cameras, Urban Echo creates a hybrid of these two things, allowing not only see into another city but maybe see yourself transported into another city or culture. A mid point between transparency and reflection, introspection and extrospection". http://www. lustlab.net/, accessed November 10th,2015. See also https://vimeo.com/23579142

6

Lev Manovich (2005), who first coined the expression "augmented space", writes: "we start slowly seeing the different species of augmented spaces being combined into one. A shopping complex leads to an interior shopping street which leads to a multiplex [...]. Although at present the small electronic screens are usually distributed throughout these spaces [...], the single larger screen [...] has a potential to unite them all, offering a kind of symbolic unity to a typically heterogeneous urban program: a shopping center + entertainmen center + hotel + residential units." More recently, Christiane Paul (2015) argues that "the use of screens, the intermedial relations they enable, and the discourses surrounding them defy merely technical explanations of the role that they play as information surfaces [...]. The role of the screen as a watchful and reactive device or as a window, mirror, or membrane is not only assigned by technicalities but by perception, which is physically and culturally shaped."

$7 \quad$ Maldiney uses hyphenation to give a particular emphasis and revea the polysemic nature of this expression. 'Co-naître' suggests both to be co-born, born together, and 'connaître' which is French for 'to know'. The author proposes an interpretation where knowledge and information are a form of becoming. "Là où il s'agit d'être le là du monde, il ne s'agit pas d'enregistrer des connaissances à son sujet, mais de co-naître à son événement-avènement" (Maldiney 1986:27).

"Proper to the event is the fact of not being repeatable, of not having iteration within time, because it founds time" (Ibid. - emphasis in the original).

9

Knowing the opposition between Benjamin and Heidegger, and the latter's indifference, or dismissal, of Husserl, under which conditions can they be brought together? Husserl's Origin is known in French through Jacques Derrida. But Derrida himself was influenced by Heidegger in his reading and deconstruction of Husserl. The partially conflicting directions create a field of tension, an active zone with blurred edges. Rather than following a line, we are immersed in a conceptual field, with a clear nucleolus - origin as the productive power.

http://www.paulsermon.org/urbanpicnic/. Accessed September 30th, 2015

11 http://www.dailytouslesjours.com/project/21-balancoires/.Accessed October 1st, 2015

12 In Man, Play and Games, Roger Callois opposes play and game as opposite ends of a play continuum. Playing is the primary power of improvisation, spontaneity and joy that is present in free play. Gaming consists on a form of play bound by rules that defines winners and losers.

13 This is the subject of much design research today. See for example Momo, a haptic navigation device that relies only on tactile feedback. http:// momobots.com/

14 See for example Sheppard (2011), a compilation of dystopian fictions about techno-centered Smart City paradigm. A more optimistic vision is pursued at MIT's Senseable City Lab, directed by Carlo Ratti. http://senseable.mit.edu/

15 On the role of origin in keeping neighbourhoods alive, see Sharon Zukin, Naked City. The death and life of authentic urban places (2010).

16 French philosopher and sociologist Edgar Morin (2006) develops the notion of "reliance" (sometimes translated as 'interlinking') as the key to achieving Felix Guattari's concept of ecosophy which expands conventional notions of ecology to embrace all dimensions of existence. "the relationship between subjectivity and its exteriority - be it social, animal, vegetable or Cosmic”. (Guattari 2000:27). 


\section{References}

Unless specified, translations from French are by the author

Benjamin, W. (1936), Art at the Age of Mechanical Reproduction. Retrieved on October 1st, 2009 from: http://design.wishiewashie.com

Benjamin, W. (1990 [1931]) The Destructive Character. (E. Jephcott). In M.W. Jennings, H. Eiland, and G. Simith (Ed.), Walter Benjamin, Selected Writings. Volume 2, Part 2. 19311934 (pp 541-42). Cambridge: Harvard University Press.

Benjamin, W. (2003 [1928]). The Origin of German Tragic Drama. Trans. John Osbourne. London: Verso.Bloomer,

K. C., \& Moore, C. W. (1977). Body, Memory and Architecture. New Haven: Yale University Press.

Callois, R. (1961). Man, Play, and Games (M. Barash, Trans.). Urbana-Champaign: University of Illinois Press.

Deleuze, G. (2006). The Fold (T. Conley, Trans.). Minneapolis: University of Minnesota Press.

Dewey, J. (2005 [1934]). Art as Experience. New York: Penguin Books.

Dunne, A. (2006 [1999]). Hertzian Tales. Electronic Products, Aesthetic Experience and Critical Design. Cambridge: The MIT Press.

Guattari, F. (2000[1999]). The Three Ecologies (I. Pindar, P. Sutton., Trans.). London: The Athlone Press.

Heidegger, M. (1993 [1964]) Building Dwelling Thinking. Basic Writings (pp. 343-364). San Francisco: Harper Collins.

Heidegger, M. (1993 [1954] The Question Concerning Technology. The Question Concerning Technology, and Other Essays (W. Lovitt, Trans.). (pp. 3-35). New York: Harper Trochbooks.

Husserl, E. (1974 [1954]), L’origine de la géométrie (J. Derrida, Trans). Paris: Presses Universitaires de France.

Ingold, T. (2007) Lines. A Brief History. London-New York: Routledge.

Maldiney, H. (1986). Art et existence. Paris: Klincksieck.

Malpas, J. (2015). Thinking Topographically - Place, Space, and Geography. Original unpublished English version of Pensar topográficamente: Lugar, espacio y geografía (P. P. Lozano, Trans.). In Documents d’Anàlisi Geogràfica, May-August 2015, vol. 61, n. 2 (pp. 199-229). Retrieved November 7th, 2015 from: http://jeffmalpas.com/downloadable-essays/ Moholy-Nagy, L. (1947). Vision in Motion. Chicago: Paul Theobald. 
Morin, E. (2006) La méthode. Tome 6: Éthique. Paris: Éditions du Seuil.

Moujan, C. (2011). From Function To Pleasure. Touch, Interaction and the Interspace. In Proceedings of DPPI Conference 2011.

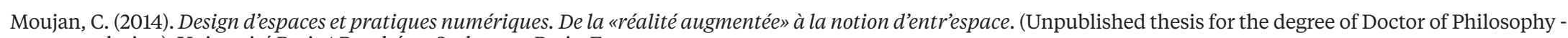
design). Université Paris 1 Panthéon-Sorbonne, Paris, France.

Rykwert, J. (2002 [2000]). The Seduction of Place. New York: Vintage Books.

Sennett, R. (2010). The Public Realm. In Gary Bridge and Sophie Watson (eds.). The Blackwell City Reader, (pp. 261-272). London: Blackwell.

Sheppard, M. (ed.) (2011). Sentient City: ubiquitous computing, architecture and the future of urban space. Cambridge: MIT Press.

Simondon, G. (1958). Du mode d'existence des objets techniques. Paris: Aubier.

Simondon, G. (1989). L’individuation psychique et collective. Paris: Aubier.

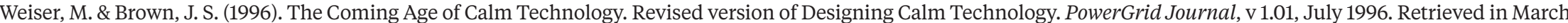
10, 2009 from: http://www.ubiq.com/hypertext/weiser/acmfuture2endnote.htm..

Zukin, S. (2010). Naked City. The Death and Life of Authentic Urban Places. New York: Oxford University Press. 